\title{
F:RRAILII
}

Mirella Salvatore · Maurizio Genuardi · Rosella Petraroli Carlo Masullo · Marco D’Alessandro

Maurizio Pocchiari

\section{Polymorphisms of the Prion Protein gene in Italian patients with Creutzfeldt-Jakob disease}

Hum Genet (1994) $94: 375-379$

In the above article there was a mistake in Table 1 on p. 376. The frequencies of Met/Val heterozygous and Val/Val homozygous controls were interchanged. The entire table is correctly printed below.

Table 1 Genotype frequencies at codon 129 in CJD patients and controls

\begin{tabular}{lrrrll}
\hline & $n$ & \multicolumn{2}{c}{ Codon 129 } & \\
\cline { 2 - 6 } & & Met/Met & Val/Val & Met/Val \\
\hline Definite CJD & 29 & $23(79.31)$ & 1 & $(3.45)$ & $5(17.24)$ \\
Probable CJD & 2 & 2 & - & - \\
Total CJD & 31 & $25(80.64)$ & 1 & $(3.23)$ & $5(16.13)$ \\
\hline Controls & 186 & $84(45.16)$ & $27(14.52)$ & $75(40.32)$ \\
\hline
\end{tabular}

M. Salvatore (저) · R. Petraroli · M. D'Alessandro · M. Pocchiari Laboratory of Virology, Istituto Superiore di Sanità,

Viale Regina Elena 299, I-00161 Rome, Italy

M. Genuardi

Istituto di Genetica, Università Cattolica del Sacro Cuore,

Rome, Italy

C. Masullo

Istituto di Neurologia, Università Cattolica del Sacro Cuore, Rome, Italy 